УДК 7.074

ББК 76.197

DOI 10.25281/2072-3156-2018-15-3-321-329

\title{
Н.А. КИСЕЛЕВА
}

\section{ФИЛОКАРТИЧЕСКАЯ КОЛЛЕКЦИЯ ПСКОВСКОГО ПРОФЕССОРА Ю.М. МУХИНА}

\author{
Надежда Анатольевна Киселева, \\ Псковский государственный университет, \\ кафедра психологии, \\ доцент \\ Ленина пл., д. 2, Псков, \\ Псковская область, 180000 , Россия \\ кандидат психологических наук, доцент \\ E-mail: kiselevana@yandex.ru
}

Реферат. Ежегодно в Псковском государственном университете проводится Международная научно-практическая конференция «Мухинские чтения», получившая свое название в честь доктора психологчческих наук, почетного профессора кафедры педагогики и психологии Юрия Михайловича Мухина. 24 июля 2018 г. ему исполнилось бы 95 лет. Многие десятилетия своей жизни он посвятил поиску и систематизации художественных открыток с изображением шедевров мирового изобразительного искусства, которые использовал в научной и педагогической деятельности. Знаменитая коллекиия открыток Ю.М. Мухина насчитывает более 12,5 тысяч экземпляров, из которых 10994 подарены вдовой ученого Псковской областной универсальной научной библиотеке (ПОУНБ), где они хранятся ныне в отделе литературы по культуре и искусству, а также в региональном иентре по работе с редкими и ценными документами ПОУНБ.
В статье рассказывается о содержании изначении данной коллекции, основная часть которой посвящена живописи, но есть серии открыток с видами графики, гравюры, скульптуры, ювелирного искусства, декоративно-прикладного творчества, книжных иллюстраций и миниатюр, фотографии и т. д. На открытках представлено широкое разнообразие живописных жанров: портреты, пейзажи, натюрморты, а также исторические, военные, религиозные, бытовые сцены. Здесь можно увидеть наборы картин как знаменитых отечественных и зарубежных художников, так и произведения малоизвестных и совсем неизвестных авторов.

Представленные репродукиии показывают, какими ценностями располагают крупнейшие мировые галереи и музеи, охватывая исторические периоды с самой древности и до конияа ХХ в., знакомят с живописными произведениями, на которых воспитаны многие поколения. Поистине коллекция Ю.М. Мухина является гордостью псковичей и представляет собой уникальную энциклопедию искусства, художественный мир в миниатюре.

Ключевые слова: Ю.М. Мухин, Мухинские чтения, ПОУНБ, ПГПИ, коллекция, открытки, искусство, живопись.

Для цитирования: Киселева Н.А. Филокартическая коллекция псковского профессора Ю.М. Мухина // Обсерватория культуры. 2018. T. 15, № 3. C. $321-329$. DOI: $10.25281 / 2072-$ 3156-2018-15-3-321-329. 


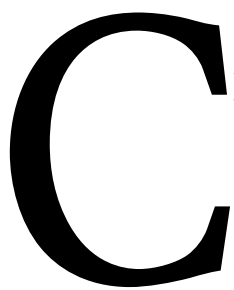

емнадцатая международная научно-практическая конференция «Мухинские чтения» состоялась 19-20 апреля 2018 г. в Псковском государственном университете. Свое название конференция получила в честь известного ученого, преподавателя Псковского государственного педагогического института им. С.М. Кирова (ПГПИ, ныне - Псковский государственный университет, ПсковГУ) Юрия Михайловича Мухина.

Юрий Михайлович Мухин (1923-1999) доктор психологических наук, почетный профессор ПГПИ, страстный коллекционер и поклонник живописи. Многие годы он посвятил поиску и систематизации художественных открыток с изображением шедевров мирового изобразительного искусства. Основной фонд его коллекции сложился в 1970-е годы. В настоящее время бо́льшая часть коллекции открыток Ю.М. Мухина располагается в отделе литературы по культуре и искусству Псковской областной универсальной научной библиотеки и насчитывает 10 тыс. 994 экз., а также в региональном центре по работе с редкими и ценными документами ПОУНБ и в Государственном архиве Псковской области $[1 ; 2]$.

Сотрудники библиотеки бережно хранят и популяризируют коллекцию, организуют выставки, презентации, круглые столы. Так, пленарное заседание конференции «Мухинские чтения - 2018» началось с доклада-презентации заведующей отделом литературы по культуре и искусству ПОУНБ Н.Г. Грищенко. Она рассказала о гордости псковичей - коллекции художественных открыток Ю.М. Мухина и ее значении для современников [3].

\section{ИЗ БИОГРАФИИ Ю.М. МУХИНА}

Ю рий Михайлович Мухин родился в городе Тюмени, но вскоре вместе с родителями переехал в Ленинград. Окончание им средней общеобразовательной школы в 1941 г. совпало с началом Великой Отечественной войны. В звании лейтенанта медицинской службы молодой боец выполнял свой долг на Белорусском и Прибалтийском фронтах. За боевые заслуги перед Отечеством Ю.М. Мухин получил орден Красной Звезды, медали и правительственные награды [1;2].

После демобилизации Юрий Михайлович поступил на философский факультет Ленинградского государственного университета, психологическое отделение которого он успешно закончил в 1952 году. С 1957 г. и до самого выхода на пенсию он работал в Псковском государственном педагогическом институте им. С.М. Кирова, где вел интенсивную и плодотворную научную и педагогическую деятельность. В 1977 г. в институте была образована кафедра психологии, выделившаяся из кафедры педагогики и психологии, куда и перешел работать на должность доцента Ю.М. Мухин. Возглавлял ее доктор психологических наук, профессор П.А. Сорокун. «Первоначально на кафедре было 6 человек, но постепенно ее состав увеличился вдвое, а в 1996 г. на базе кафедры был создан психолого-педагогический факультет» [4, с. 7]. В 1978 г. Юрий Михайлович получил звание профессора, а в 1997 г. ему торжественно присвоили звание почетного профессора ПГПИ.

Свои научные труды ученый связал с исследованием психологических механизмов и закономерностей движения руки и глаза, с проблемами зрительного восприятия и воспроизведения пространственных свойств на рисунке, что явилось следствием одного из его любимейших увлечений - художественного творчества. Докторская диссертация Ю.М. Мухина посвящена исследованию связи отражательной и регулирующей функции зрительного восприятия, включенного в целостную перцептивно-практическую художественную деятельность [5].

Изучение факторов и условий обучения рисованию людей разного возраста привело ученого к заключению, что установление продуктивной связи между процессами восприятия и изображения представляет собой построение регулирующего образа, организацию его функции регулирования и управления через преобразование видимого на натуре в изображение на рисунке. Выявление психологических особенностей процессов и структур, через которые возникает и реализуется такой образ, и составило центральную задачу диссертации Ю.М. Мухина.

В ходе исследования были получены значимые теоретические и практические результаты, обладающие высокой степенью науч- 
ной новизны. Так, выявлена иерархическая последовательность накопления инвариантных характеристик регулирующего образа в условиях обучения рисованию взрослых и детей; установлены факты и закономерности динамики и маршрутов зрительных осмотров в процессе рисования; выявлена взаимосвязь между функционально-динамическими состояниями зрительной системы человека при восприятии реального объема фигур и при восприятии плоскостных изображений трехмерных объектов; изучены психологические механизмы восприятия человеком реальных и нарисованных изображений и т. д. [5]. С подробными результатами исследований Ю.М. Мухина можно ознакомиться в текстах его научных статей и диссертаций, которые хранятся в Российской государственной библиотеке в Москве [5-10].

Интересы и увлечения Юрия Михайловича были очень разносторонними, что позволяло современникам сравнивать его с месторождением драгоценных камней, один удивительнее другого. По воспоминаниям его жены, он самостоятельно конструировал и вручную собирал мощные телескопы, через которые часами напролет наблюдал за звездами, вел систематические астрономические наблюдения и переписку с другими астрономами, научными журналами и астрономическим обществом $[1 ; 2]$. Ю.М. Мухин много путешествовал и делал замечательные фотографии красивейших уголков нашей страны. Он увлекался изучением минералов и самостоятельно собрал значительную их коллекцию в горах Урала, Алтая, Средней Азии, Дальнего Востока, а также на просторах Псковской области. Многие десятилетия исследователь посвятил поиску и систематизации художественных открыток с изображением шедевров мирового изобразительного искусства.

\section{СОДЕРЖАНИЕ КОЛЛЕКЦИИ ОТКРЫТОК Ю.М. МУХИНА}

$\mathrm{B}$ настоящее время бо́льшая часть коллекции открыток Ю.М. Мухина подарена вдовой ученого Псковской областной универсальной научной библиотеке. Хранятся открытки в 14-ти плотно заполненных библи-

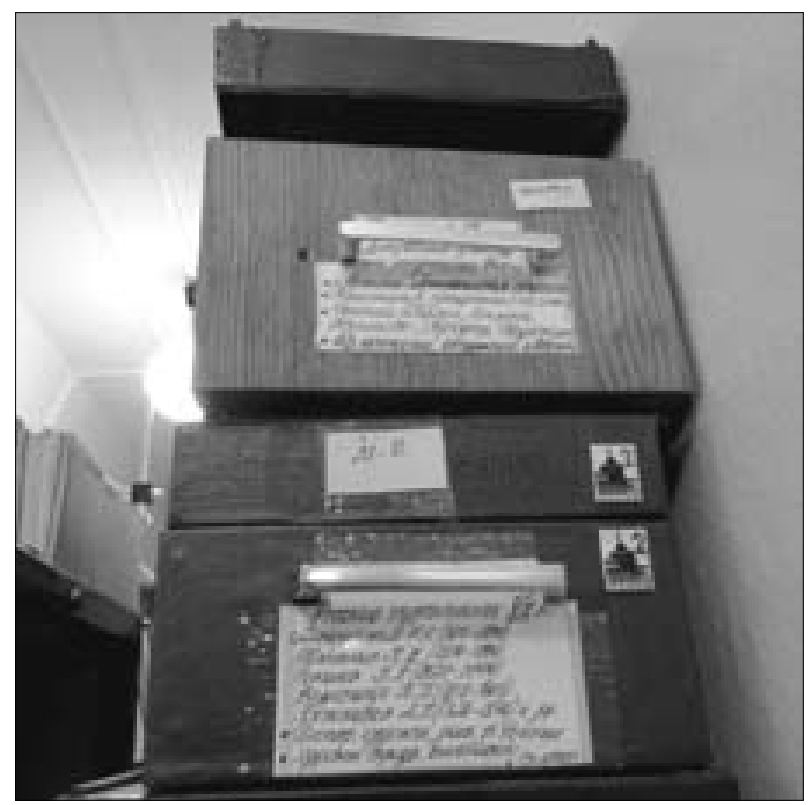

Часть коллекции открыток Ю.М. Мухина в ПоУНБ. Автор фото: Н.А. Киселева

отечных ящиках, где они тщательно рассортированы по годам и темам и размещены на полках рядом с другими печатными изданиями. Здесь можно увидеть классические наборы цветных и черно-белых открыток в обложках по 10-25 штук, которые выпускались издательствами «Аврора», «Художник РСФСР», «Советский художник», посвященных русской, советской и зарубежной живописи.

Коллекция включает комплекты открыток из серий «Государственная Третьяковская галерея», «Государственный Эрмитаж», «Государственный Русский музей», «Государственный музей изобразительных искусств им. А.С. Пушкина», «Государственный музей искусства народов Востока», «Русская живопись в музеях РСФСР», «Музеи мира». Отдельные наборы посвящены коллекциям картин из крупнейших музеев и галерей: Центрального музея древнерусской культуры и искусства им. Андрея Рублева, санкт-петербургского Музея антропологии и этнографии им. Петра Великого (Кунсткамера), Грановитой палаты Московского Кремля, Национального музея искусств им. Богдана и Варвары Ханенко (бывшее название - Киевский музей западного и восточного искусства), Одесского художественного музея, Вологодской областной картинной галереи, Пермской государственной художествен- 
ной галереи и др. Присутствуют также вырезки из газет и журналов, отдельные поздравительные открытки и фотографии, аккуратно подклеенные на картонную основу и собственноручно подписанные Юрием Михайловичем. Многие из них являются уникальным информационным материалом.

В региональном центре по работе с редкими и ценными документами ПОУНБ хранится несколько десятков старинных открыток, собранных Ю.М. Мухиным. Среди них: печатная продукция издательства «Ришарь» Р. Голикс и А. Вильбор (Петроград, Санкт-Петербург); художественные издания «Зингерь»; издания художников А.В. Маковского и А.И. Лажечникова (Санкт-Петербург); И.С. Лапина (Париж, Люксембург); Н.К. Константинова, Т. Строфер, а также зарубежные открытки с надписями на иностранных языках из Англии, Италии, Китая, Японии и других стран.

На открытках представлены черно-белые и цветные репродукции дореволюционных картин Я.И. Бровара, В.Е. Маковского, Ф. Ворринга, К. Швенингера и других художников. Имеются экземпляры с сюжетами военных и мирных бытовых сцен, рекламные открытки обувной и гильзовой фабрик, открытки с иллюстрированными пословицами и загадками, фотографии известных людей.

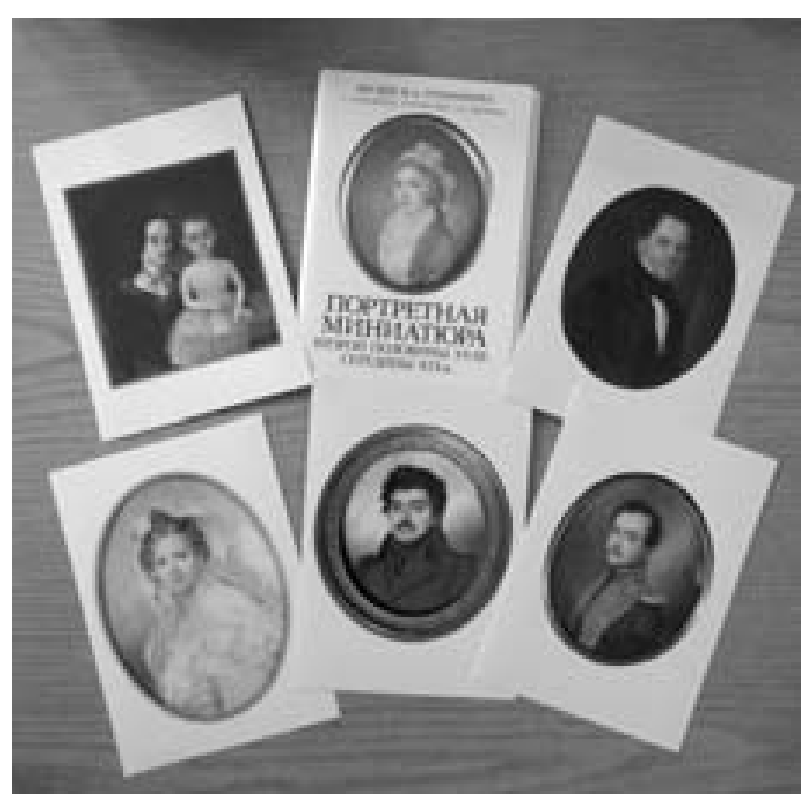

Набор открыток «Портретная миниатюра второй половины XVIII - середины XIX в.» из коллекции Ю.М. Мухина. Автор фрото: Н.А. Киселева

\section{ЗНАЧЕНИЕ КОЛЛЕКЦИИ OTКРЫТОК Ю.М. МУХИНА}

$\Pi$ редставленные репродукции показывают, какими художественными ценностями располагают галереи, музеи, пинакотеки, коллекции, охватывающие все этапы развития мирового искусства, знакомят с живописными произведениями, на которых воспитаны многие поколения [11]. Коллекция Ю.М. Мухина является гордостью псковичей и представляет художественный мир в миниатюре.

По открыткам коллекции наглядно можно изучать историю искусства, начиная с самой древности и до конца XX века. Основная ее часть посвящена живописи, но есть серии открыток с видами графики, гравюры, скульптуры, ювелирного искусства, декоративно-прикладного творчества, книжных иллюстраций и миниатюр, фотографии и т. д. На открытках представлено широкое жанровое разнообразие: портреты, пейзажи, натюрморты, исторические, религиозные, бытовые сцены. Только список художников, репродукции которых входят в коллекцию Ю.М. Мухина, занял бы не один десяток страниц печатного текста.

Определенные разделы из коллекции открыток посвящены художественным школам и объединениям: «Иконопись Псковской школы», «Школа Венецианова», «Товарищество передвижных художественных выставок», «Союз русских художников», «Союз художников СССР», «Иностранные художники, работающие в России», художники Беларуси, Казахстана, Литвы, Украины и др. Широко представлено западноевропейское и восточное искусство Англии, Германии, Голландии, Греции, Дании, Испании, Италии, Польши, Румынии, Финляндии, Фландрии, Франции, Чехии, Швеции, а также США и многих других стран, сопровождаемое надписями на русском и иностранном языках.

Открытки не только составляют неотьемлемую часть культуры и быта народов и стран, но и сами являются их отражением. Старые открытки, кропотливо собранные коллекционерами, могут иной раз больше рассказать о своем времени, чем документальные хроники и мемуары [11]. Здесь можно увидеть 
самые волнующие моменты из жизни людей, запечатленные художниками и фотографами, а также проследить этапы культурно-исторических событий в нашей стране, тщательно систематизированные Юрием Михайловичем по конкретным разделам: «История русского военного флота. Художник И. Родионов», «Юность вождя. Рисунки Н. Жукова», «Байкало-Амурская магистраль. Изорепортаж художника И. Титова», «Декабристы. Санкт-Петербург пушкинской поры», «Памятники героям Великой Отечественной войны», «Из истории открытки» и т. д.

Для краеведов представляют интерес наборы открыток, посвященные Псковщине, где Ю.М. Мухин жил и работал много лет: «Иконопись Псковской школы», «Псков в картинах советских художников», «Пушкиногорье», «Великим Лукам - 800 лет» и др.

Часть мухинской коллекции с видами достопримечательностей Пскова и других городов в настоящее время находится в Государственном архиве страхового фонда и аудиовизуальных документов Псковской области и включает 109 ед. хранения (1409 открыток) [1]. В описи выделены восемь разделов: наборы открыток с видами города Пскова за 1965-1990 гг., с видами поселка Пушкинские горы и Пушкиногорского заповедника за 1961-1987 гг., наборы открыток «Музеи А.С. Пушкина» за 1968-1987 гг., виды Ленинграда за 1963-1990 гг., пригороды Ленинграда (Петродворец, Пушкин, Павловск) за 1968-1983 гг., виды города Вологды 1971 г., Бухары 1983 г. и набор открыток «Зодчество Древней Руси» за 1987 год.

Наибольшее значение представляет раздел с видами Пскова, включающий 27 наборов открыток, из которых самыми ценными являются: почтовая черно-белая открытка «Троицкий собор. 1699» с фотографией Троицкого собора и рыболовецкого причала у стен Псковского Кремля; набор открыток «Псков. Храмы» из серии «Взгляд из прошлого», куда включено 16 черно-белых фотографий начала XX в., сделанных фотографом М. Герасимовым [1].

Многолетнее хобби коллекционирования Ю.М. Мухин сочетал с глубокими познаниями в области искусствоведения. Об этом говорят его многочисленные записи и пометки на открытках; биографии художников, по крупицам собранные из разных источников, написанные им на отдельных карточках от руки; обобщающие таблицы и схемы, позволяющие систематизировать богатейший художественный материал. И все это лишь малая часть проделанного им титанического труда, плоды которого сегодня можно увидеть в его филокартическом собрании.

Конечно, формировать такую значительную коллекцию открыток в советское время было нелегко. Однако это могло быть единственной возможностью познакомиться с шедеврами искусства, хранящимися в разных городах и странах. Нашим современникам в этом смысле повезло гораздо больше - появление компьютеров и цифровых гаджетов стало альтернативой коллекционированию и многократно расширило информационное пространство. И пусть изображение на открытках или электронных носителях ни в коей мере не заменит созерцания оригиналов в натуральную величину, тем не менее оно дает общее представление об образе, делает их узнаваемыми, а также помогает восстановить в памяти, если знакомство с оригиналом уже состоялось.

В дополнение к научно-исследовательским задачам, которые решались Ю.М. Мухиным с помощью экземпляров коллекции, на современном этапе ее значение расширилось, приобретя биографическую, общеобразовательную, культурно-историческую, искусствоведческую, воспитательно-патриотическую ценность.

\section{ФИЛОКАРТИЧЕСКОЕ НАСЛЕДИЕ ВЕЛИКОГО УЧЕНОГО И СОВРЕМЕННОСТЬ}

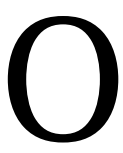

дним из значительных факторов успешного развития библиотек является социальное партнерство с различными организациями и объединениями [1214]. В 2009 г. в рамках совместного проекта ПОУНБ и Псковского государственного объединенного историко-архитектурного и художественного музея-заповедника открылась выставка «Мир в художественной открытке», на которой были выставлены 83 экспоната из коллекции Ю.М. Мухина [11]. 


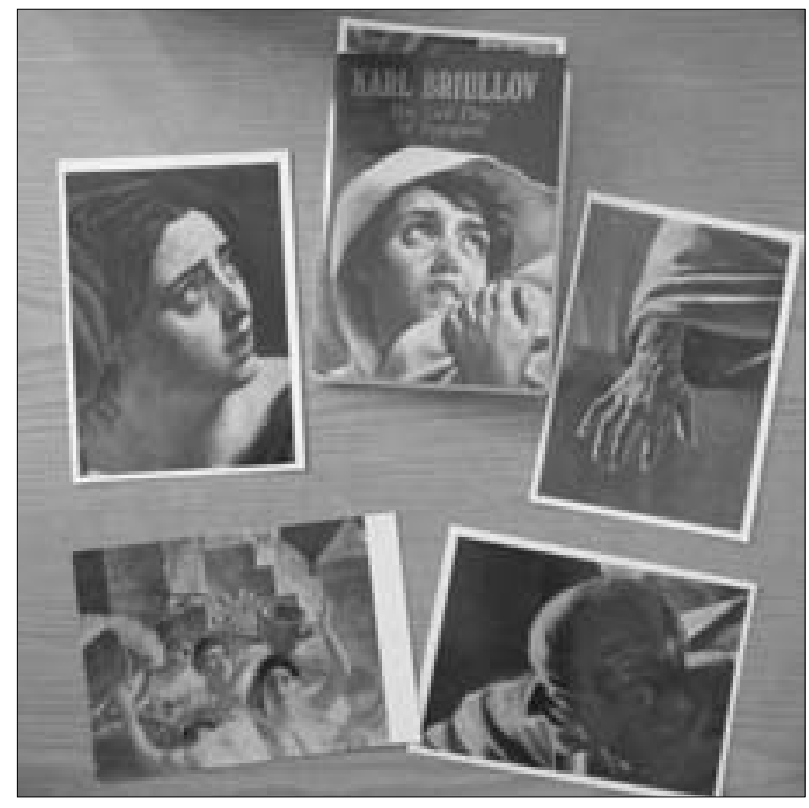

Набор открыток с репродукциями деталей картины К.П. Брюллова «Последний день Помпеи» из коллекции Ю.М. Мухина. Автор фрото: Н.А. Киселева

Заведующая отделом литературы по культуре и искусству ПОУНБ Н.Г. Смелягина и библиограф Т.Г. Леденина отметили, что на выставке представлены открытки XIX - начала $\mathrm{XX}$ в. [15]. В основном, это фоторепродукции зарубежных и отечественных мастеров по темам: русские сказки, песни, пословицы; исторические сюжеты; народные, государственные и церковные праздники; своеобразие русской природы, быта; различные нации и народности; типичные пейзажи с монастырями, церквями, деревнями, отражающие характерные для открыток того времени виды.

Почетный гражданин города Пскова, краевед Н.Ф. Левин в своем интервью отметил, что «эта выставка - лишнее подтверждение значимости коллекционирования, его ценности для сохранения исторической памяти» [15]. Вслед за этим событием в ПОУНБ состоялась презентация открыток профессора Ю.М. Мухина, на которой все желающие могли познакомиться с полной коллекцией этого замечательного ученого.

В 2017 г. на базе отдела литературы по культуре и искусству ПОУНБ открылся клуб филокартистов - любителей коллекционирования, изучения и систематизации открыток [16]. Первое заседание руководитель клуба
В.И. Горбачева посвятила рассказу о коллекции профессора психологии ПГПИ, экспонаты которой систематически представляются на выставках, посвященных самым разнообразным праздничным и памятным датам.

Доброй традицией в ПОУНБ стал выпуск «Календаря знаменательных и памятных дат», где в хронологическом порядке (по новому стилю) приведены информация и текстовые гиперссылки на памятные, юбилейные даты, исторические личности, праздничные события текущего месяца [17]. Издание предназначено для работников библиотек, культурно-просветительских учреждений, редакций журналов, газет, преподавателей и снабжено краткой исторической справкой и иллюстративным материалом. При разработке «Календаря знаменательных и памятных дат на 2013 г.» использовались открытки из личных собраний библиофила Р.В. Полчанинова и профессора Ю.М. Мухина, коллекции которых находятся в фондах ПОУНБ [18].

Современные студенты Псковского государственного университета - будущие психологи знакомятся с биографией и коллекцией известного ученого в рамках учебных курсов по истории психологии и арт-терапии со своим преподавателем, доцентом кафедры психологии ПсковГУ Н.А. Киселевой [19-21].

Использование открыток в качестве наглядного материала может быть полезно при изучении целого ряда учебных предметов и научных дисциплин, в том числе психологических, что широко использовал в своей педагогической деятельности сам Юрий Михайлович. Он демонстрировал студентам на занятиях по психологии изображенные на открытках особенности внешнего вида представителей многих профессий, национальностей, социальных слоев из разных исторических эпох, особенности их эмоциональных состояний, мимики, жестов, телесных поз, поведения и межличностных отношений. Уже само неторопливое внимательное разглядывание красочных открыток коллекции развивает полет воображения, заставляет задуматься, приобщает к прекрасному миру искусства и творчества и оказывает благоприятное психотерапевтическое воздействие. 
Таким образом, знаменитая коллекция открыток Юрия Михайловича Мухина - это уникальное филокартическое наследие, часть мировой культуры, которая продолжает привлекать внимание и радовать почитателей искусства, истории, психологии и просто любознательных людей, щедро делясь с ними образцами лучших творений величайших мастеров и способствуя восстановлению прошлого и развитию культурной жизни Псковской земли и России в целом.

\section{Список источников}

1. Мухин Юрий Михайлович (1923-1999), доктор психологических наук, профессор Псковского государственного педагогического института им. С.М. Кирова (1957-1999), участник Великой Отечественной войны 1941-1945 гг. // Государственный архив страхового фонда и аудиовизуальных документов Псковской области. Ф. 3. Оп. 2-ПИ ОТ. Д. 1.

2. Мухин Юрий Михайлович (1923-1999), доктор психологических наук, профессор Псковского государственного педагогического института им. С.М. Кирова (1957-1999) // Государственный архив новейшей истории Псковской области. Ф. 9763. Оп. 1. Д. 9; 11.

3. Грищенко Н.Г. Мир художественной открытки профессора Мухина [Электронный ресурс] // Псковская областная универсальная научная библиотека : сайт. URL: http://pskovlib.ru/ events/meropriyatiya_biblioteki/22760/ (дата обращения: 19.04.2018).

4. Киселева Н.А. Поколение, опаленное войной: к 95-летнему юбилею Прокопия Афанасьевича Сорокуна // Вестник Псковского государственного университета. Серия : Психолого-педагогические науки. 2016. № 3. С. 3-11.

5. Мухин Ю.М. Восприятие и воспроизведение пространственных свойств на рисунке : автореф. дис. ... д-ра психол. наук. Ленинград, 1974. 36 с.

6. Мухин Ю.М. Инвариантность и отражательная функция зрительного образа // Психология познавательной деятельности : сборник научных статей / Лен. гос. пед. ин-т им. А.И. Герцена. Ленинград, 1965. С. 5-15.

7. Мухин Ю.М. О развитии изобразительной линии в рисунках учащихся I-IV классов // Ученые записки Псковского государственного педагогического института. Псков, 1963. Вып. 15. С. 62-66.
8. Мухин Ю.М. О двух типах двигательного поведения глаза при определении пропорций формы // Ученые записки Псковского государственного педагогического института. Псков, 1968. Вып. 39. С. 82-92.

9. Мухин Ю.М. Исследование движений руки и глаз при решении простейших изобразительных задач // Вопросы психологии. 1968. № 5 . C. $128-134$.

10. Мухин Ю.М. Некоторые особенности проявления пространственной асимметрии в перцептивно-графических действиях // Вопросы педагогики и психологии : [сб. статей]. Псков, 1971. T. 477. С. 102-112.

11. Смелягина Н.Г. Весь мир на открытке : о коллекции Ю.М. Мухина, профессора Псковского педагогического университета // Библиотечное дело. 2010. № 17. С. 28-30.

12. Дубовенко В.А., Курбангалеева И.В., Юдина И.Г. Социальное партнерство - фактор успешного развития академической библиотеки // Библиотековедение. 2017. Т. 66, № 5. С. 487-495. DOI: 10.25281/0869-608X-2017-66-5-487-495.

13. Иванова Е.А. От истоков книгопечатания до библиотечных инноваций XXI века: «Румянцевские чтения - 2017»// Библиотековедение. 2017. T. 66, № 3. С. 256-262. DOI: 10.25281/0869-608X-2017-66-3-256-262.

14. Половникова И.А. 25 лет Юдинским чтениям // Библиотековедение. 2015. № 6. C. 71-73. DOI: 10.25281/0869-608X-2015-0-6-71-73.

15. Фоторепортаж: открытие выставки «Мир в художественной открытке» [Электронный ресурс] // Россия начинается здесь! Псковская земля : сайт. URL: http://culture.pskov.ru/ru/ news/event/5850 (дата обращения: 04.05.2018).

16. Клуб филокартистов открылся в Псковской областной библиотеке [Электронный ресурс] // Псковская лента новостей : сайт. URL: http:// pln-pskov.ru/culture/266733.html (дата обращения: 12.03.2018).

17. Календарь знаменательных и памятных дат по Пскову и Псковской области на 2018 г. [Электронный ресурс] // Централизованная библиотечная система города Пскова : сайт. URL: http://bibliopskov.ru/calendar2018-pskov.htm (дата обращения: 15.05.2018).

18. Календарь знаменательных и памятных дат на 2013 год [Электронный ресурс] // Библиотечный портал Псковской области. URL: 
http://portal.pskovlib.ru/pskov/2564-kalendarznamenatelnih-i-pamyatnih-dat-na-2013-god (дата обращения: 15.05.2018).

19. Знакомство студентов с коллекцией открыток Ю.М. Мухина [Электронный ресурс] // Псковский государственный университет. Факультет естественных наук, медицинского и психологического образования : сайт. URL: http://fenmpo.pskgu.ru/page/a096d0a0803f-4ee6-ac77-b0a05ff927ec (дата обращения: 16.05.2018).
20. Киселева Н.А. Динамика эмоциональных состояний приемных детей, воспитывающихся в замещающих семьях // Вопросы психологии. 2015. № 4. C. $70-80$.

21. Киселева Н.А. Развитие психолого-педагогической компетентности субъектов образования : учеб. пособие. Псков : Псковский гос. пед. ун-т, 2010. 173 c.

Иллюстрации предоставлены автором статьи

\section{Deltiological Collection of Pskov Professor Yury Mukhin}

\section{Nadezda A. Kiseleva}

Pskov State University, 2, Lenina Square, Pskov, 180000, Russia

E-mail: kiselevana@yandex.ru

\begin{abstract}
Every year the Pskov State University hosts the International scientific and practical conference "Mukhin readings", which received its name in honor of the Doctor of psychological Sciences, Honorary Professor of the Department of pedagogics and psychology Yury Mikhailovich Mukhin. He would have turned 95 on July 24, 2018. He devoted many years of his life to the search and systematization of art postcards with the images of masterpieces of world art, which he used in scientific and pedagogical activities. The famous collection of Y.M. Mukhin includes more than 12500 postcards; 10994 of them were donated by the widow of the scientist to the Pskov regional universal scientific library (PRUSB), where they are now kept in the Department of literature on culture and art, as well as in the Regional Center for work with rare and valuable documents of PRUSB.
\end{abstract}

The article describes the content and value of this collection, the main part of which is devoted to paintings, but there are series of postcards with graphics, engravings, sculpture, jewelry, arts and crafts, book illustrations and miniatures, photos, etc. The cards represent a wide variety of pictorial genres: portraits, landscapes, still life, as well as historical, military, religious, domestic genre scenes. You can see here the paintings by famous Russian and foreign artists, as well as works of little-known and unknown authors. The presented reproductions demonstrate the values that the world's largest galleries and museums have, covering historical periods from ancient times to the end of the 20th century, and acquaint with the paintings, on which many generations were brought up. Truly, the collection of Y.M. Mukhin is the pride of the people of Pskov and is the unique encyclopedia of art, the art world in miniature.

Key words: Y.M. Mukhin, Mukhin Readings, Pskov Regional Universal Scientific Library, Pskov State University, Collection, Postcards, Art, Painting. Citation: Kiseleva N.A. Deltiological Collection of Pskov Professor Yury Mukhin, Observatory of Culture, 2018, vol. 15, no. 3, pp. 321-329. DOI: $10.25281 / 2072-3156-2018-15-3-321-329$.

\section{References}

1. Mukhin Yury Mikhailovich (1923-1999), doktor psikhologicheskikh nauk, professor Pskovskogo gosudarstvennogo pedagogicheskogo instituta im. S.M. Kirova (1957-1999), uchastnik Velikoi Otechestvennoi voiny 1941-1945 gg., Gosudarstvennyi arkhiv strakhovogo fonda i audiovizual'nykh dokumentov Pskovskoi oblasti [State Archive of the Insurance Fund and Audiovisual Documents of the Pskov Region]. Coll. 3, aids 2-PI OT, fol. 1.

2. Mukhin Yury Mikhailovich (1923-1999), doktor psikhologicheskikh nauk, professor Pskovskogo gosudarstvennogo pedagogicheskogo instituta im. S.M. Kirova (1957-1999), Gosudarstvennyi arkhiv noveishei istorii Pskovskoi oblasti [State Archive of Contemporary History of the Pskov Region]. Coll. 9763, aids 1, fols. 9, 11. 
3. Grishchenko N.G. The world of the art postcard of Professor Mukhin, Pskovskaya oblastnaya universal'naya nauchnaya biblioteka [The Pskov Regional Universal Scientific Library - official site]. Available at: http://pskovlib.ru/events/meropriyatiya_biblioteki/22760/ (accessed 19.04.2018) (in Russ.).

4. Kiseleva N.A. "Generation, Burnt by War" to the 95th Anniversary of Procopius Afanasievich Sorokhuna, Vestnik Pskovskogo gosudarstvennogo universiteta. Seriâ Social'no-gumanitarnye nauki [The Herald of Pskovsk State University. Series of Psihologo-Pedagogical Sciences], 2016, no. 3, pp. 3-11(in Russ.).

5. Mukhin Yu.M. Vospriyatie i vosproizvedenie prostranstvennykh svoistv na risunke [Perception and Reproduction of Spatial Properties in the Figure], Doct. psychological sci. diss. Abstr. Leningrad, 1974. 36 p.

6. Mukhin Yu.M. Invariance and Reflective Function of the Visual Image, Psikhologiya poznavatel'noi deyatel'nosti [Psychology of Cognitive Activity: coll. of articles]. Leningrad, 1965, pp. 5-15 (in Russ.).

7. Mukhin Yu.M. On the development of the fine line in the drawings of pupils of 1-4 grades, Uchenye zapiski Pskovskogo gosudarstvennogo pedagogicheskogo institu$\mathrm{ta}$ [Scientific notes of the Pskov State Pedagogical Institute]. Pskov, 1963, issue 15, pp. $62-66$ (in Russ.).

8. Mukhin Yu.M. Two Types of the Eye Motor Behavior in Determining the Form Proportions, Uchenye zapiski Pskovskogo gosudarstvennogo pedagogicheskogo instituta [Scientific Notes of the Pskov State Pedagogical Institute]. Pskov, 1968, issue 39, pp. 82-92 (in Russ.).

9. Mukhin Yu.M. Investigation of Hands and Eyes Movements in Solving the Simplest Representational Problems, Voprosy psikhologii [Issues of Psychology], 1968, no. 5, pp. 128-134 (in Russ.).

10. Mukhin Yu.M. Some Features of the Spatial Asymmetry Manifestation in Perceptually-Graphic Actions, Voprosy pedagogiki i psikhologii [Issues of Pedagogy and Psychology: Collection of Articles]. Pskov, 1971, vol. 477, pp. 102-112 (in Russ.).

11. Smelyagina N.G. The Whole World on a Postcard: about the Collection of the Professor of the Pskov Pedagogical University Yu.M. Mukhin, Bibliotechnoe delo [Librarianship], 2010, no. 17, pp. 28-30 (in Russ.).

12. Dubovenko V.A., Kurbangaleeva I.V., Yudina I.G. Social Partnership as a Factor of Successful Development of Academic Library, Bibliotekovedenie [Library and Information Science (Russia)], 2017, vol. 66, no. 5, pp. 487-495. DOI: 10.25281/0869608X-2017-66-5-487-495 (in Russ.).

13. Ivanova E.A. From Rise of Book Printing to Library Innovations of the 21st century: "Rumyantsev Readings - 2017", Bibliotekovedenie [Library and Information Science (Russia)], 2017, vol. 66, no. 3, pp. 256-262. DOI: $10.25281 / 0869-608 \mathrm{X}-2017-$ 66-3-256-262.

14. Polovnikova I.A. The 25th Anniversary of Yudin Readings, Bibliotekovedenie [Library and Information Science (Russia)], 2015, no. 6, pp. 71-73. DOI: 10.25281/0869-608X-2015-0-6-71-73 (in Russ.).

15. Photo-Report: Opening of the Exhibition "The World in an Art Postcard", Rossiya nachinaetsya zdes'! Pskovskaya zemlya [Russia Begins Here! Pskov Land: official site]. Available at: http://culture.pskov.ru/ru/ news/event/5850 (accessed 04.05.2018) (in Russ.).

16. Filokartist Club Opened in the Pskov Regional Library, Pskovskaya lenta novostei [Pskov News Line: site]. Available at: http://pln-pskov.ru/culture/266733. html (accessed 12.03.2018) (in Russ.).

17. Calendar of Significant and Memorable Dates for Pskov and Pskov Region for 2018. Tsentralizovannaya bibliotechnaya sistema goroda Pskova [Centralized Library System of the city of Pskov: website]. Available at: http://bibliopskov.ru/calendar2018pskov.htm (accessed 15.05.2018) (in Russ.).

18. Calendar of Significant and Memorable Dates for 2013, Bibliotechnyi portal Pskovskoi oblasti [Library portal of the Pskov Region]. Available at: http://portal.pskovlib.ru/pskov/2564-kalendarznamenatelnih-i-pamyatnih-dat-na-2013-god (accessed 15.05.2018).

19. Students Acquaintance With the Yu.M. Mukhin Postcards Collection, Pskovskii gosudarstvennyi universitet. Fakul'tet estestvennykh nauk, meditsinskogo i psikhologicheskogo obrazovaniya [Pskov State University. Faculty of Natural Sciences, Medical and Psychological Education: site]. Available at: http:// fenmpo.pskgu.ru/page/a096d0a0-803f-4ee6-ac77b0a05ff927ec (accessed 16.05.2018) (in Russ.).

20. Kiseleva N.A. Emotional States Dynamics of Children Lacking Parents' Care, Who is Brought up in Substituting Families, Voprosy psikhologii [Issues of Psychology], 2015, no. 4, pp. 70-80 (in Russ.).

21. Kiseleva N.A. Razvitie psikhologo-pedagogicheskoi kompetentnosti sub"ektov obrazovaniya [The Development of Psycho-Pedagogical Competence of Educational Subjects]. Pskov, Pskovskii gos. ped. un-t Publ., 2010, 173 p. 